\title{
Enhancing biogas plant production using pig manure and corn silage by adding wheat straw processed with liquid hot water and steam explosion
}

\author{
Michał Gaworski ${ }^{1}$, Sławomir Jabłoński ${ }^{1}$, Izabela Pawlaczyk-Graja ${ }^{2}$, Rafał Ziewiecki ${ }^{2}$, Piotr Rutkowski ${ }^{3}$,
} Anna Wieczyńska², Roman Gancarz ${ }^{2}$ and Marcin Łukaszewicz ${ }^{1^{*}}$ (i)

\begin{abstract}
Background: Pig manure utilization and valorization is an important topic with tightening regulations focused on ecological and safety issues. By itself pig manure is a poor substrate for biogas production because of its excessive nitrogen content relative to available organic carbon. Such substrate is alkaline, and methanogenesis can be suppressed, and so additional substrates with high organic carbon must be added. The most promising is straw, which is available from adjacent biogas plant cultures. However, the abundant lignocellulosic biomass of wheat straw undergoes slow decomposition, and only a fraction of the chemical energy can be converted into biogas; thus economical methods for pretreatment increasing bioavailability are sought.
\end{abstract}

Results: A method was investigated to increase the methane yield in a full-scale plant for co-fermenting pig manure with corn silage, which was the default substrate in the original source reactors. Increased lignocellulosic bioavailability of wheat straw was achieved by combining liquid hot water (LHW) and steam explosion (SE). According to FT-IR analysis, the treatment resulted in hemicellulose hydrolysis, partial cellulose depolymerization, and lignin bond destruction. Low-mass polysaccharides $\left(0.6 \times 10^{3} \mathrm{~g} \mathrm{~mol}^{-1}\right)$ had significantly higher concentration in the leachate of LHW-SE wheat straw than raw wheat straw. The methanogenic potential was evaluated using inoculum from two different biogas plants to study the influence of microorganism consortia. The yield was 24-34\% higher after the pretreatment process. In a full-scale biogas plant, the optimal conditions were $\sim 165^{\circ} \mathrm{C}, 2.33 \mathrm{MPa}$, and $10 \mathrm{~min}$ in LHW and $\sim 65^{\circ} \mathrm{C}$ and $\sim 0.1 \mathrm{MPa}$ for SE. The processes did not generate detectable inhibitors according to GC-MS analysis, such as furfural and 5-hydroxymethylfurfural.

Conclusions: The LHW-SE combined pretreatment process increases the bioavailability of carbohydrates from wheat straw. The LHW-SE treated wheat straw gave similar biogas yields to corn silage, thus enables at least partial replacement of corn silage and is good for diversification of substrates. Surprisingly, microorganisms consortia from other biogas plant fed with other substrates may have higher efficiency in utilization of tested substrate. Thus, methanogenic consortia may be considered in the process of optimization at industrial scale. The efficiency was calculated, and the LHW-SE may be profitable at full industrial scale and further optimization is proposed.

Keywords: Lignocellulosic biomass pretreatment, Steam explosion, Liquid hot water extraction, Methane production, Wheat straw

\footnotetext{
*Correspondence: marcin.lukaszewicz@uwr.edu.pl

1 Department of Biotransformation, Faculty of Biotechnology, University

of Wrocław, Fryderyka Joliot-Curie 14a, 50-383 Wrocław, Poland

Full list of author information is available at the end of the article
} 


\section{Background}

The profitability of biogas plants in the European Union using biomass could be compromised without preferential regulations or market fluctuations, such as establishing low prices of green certificates [1]. Environmentally, the most advantageous option is processing organic waste in biogas plants instead of dedicated biomass grown on fields. However, the production capacity of biogas from waste may be too low for a biogas plant to be profitable. Therefore, there is a need for process optimization and the use of additional substrate [2,3].

Biogas substrates vary in terms of the decomposition rate and in methane production yield. Therefore, a combination of feed additives and pretreatment methods should give the highest efficiency of a biogas production while reducing the decomposition time required for a substrate [4]. There are several methods of substrate pretreatment to improve the decomposition and methane yield [5]. However, for application on an industrial scale, these methods must be evaluated in terms of net energy gain and economic viability.

Pig manure alone is a poor substrate for biogas production, because of its excessive nitrogen content relative to available organic carbon. In addition high nitrogen content may result in toxic level of ammonia. Thus, additional substrates with high organic carbon must be added. The most promising is straw, which is available from adjacent biogas plant cultures [6]. However, the abundant lignocellulosic biomass of wheat straw undergoes slow decomposition, and only a fraction of the chemical energy can be converted into biogas. Increased lignocellulosic biomass conversion may be achieved by pretreatment methods such as liquid hot water (LHW) and steam explosion (SE) $[7,8]$. The aim of this study is to-find alternatives and more economical methods for methane production for the Koczała full-scale biogas plant (POLDANOR; Poland) using pig manure and corn silage. For this purpose, the structural changes and the methanogenic potential in treated and untreated materials were investigated.

Novelty of our research results from the analysis of the impact of LHW-SE pre-treatment processing of wheat straw on its real biogas yield potential in the full-scale biogas plant with its comprehensive analysis. To date there are many studies which try to predict theoretically how particular substrate after pretreatment would behave in a full-scale biogas plant $[9,10]$ which are provided in small scale plants and laboratory studies. They point out the need to confront their assumptions with a full-scale plant results [11]. As shown in our research theoretical and real estimations are not consistent and the theoretical yield of biogas proved to be underestimated.

\section{Methods}

Raw material

Wheat straw (Triticum aestivum L.) was kindly supplied by the farms of Poldanor S. A. (Człuchów County, Pomorskie Voivodeship, Poland). The straw was dried in the field under the atmospheric conditions of a hot, dry summer and then stored in warehouse until use. The dry matter content of the wheat straw was $93.30 \% \pm 0.20 \%$. For LHW-SE pretreatment, light yellow, non-moldy wheat straw was chopped into approximately $10-\mathrm{mm}$ pieces by a crop chopper ("DOZAMECH", Odolanów, Poland). Recycled water was used in the LHW-SE pretreatment, which was obtained by mechanically squeezing post-fermentation sludge from a biogas plant.

\section{Liquid hot water-steam explosion pretreatment of wheat straw}

LHW-SE pretreatment of the wheat straw was carried out in an industrial-scale combined installation (Koczała agricultural biogas plant, Poldanor S. A., Przechlewo, Poland). The concept of the plant construction is based on the general principles of the LHW and SE processes [12]. Briefly, the ground, dry wheat straw and recycled water were moved through a pipe reactor by a set of highpressure pumps $(2.33 \mathrm{MPa})$ with temperature maintained under the boiling point $\left(\sim 165^{\circ} \mathrm{C}\right)$. The retention time in the pipe reactor was about $10 \mathrm{~min}$ to maintain the severity factor at the point where the inhibitors of the methane fermentation process are not produced, such as furfurals and 5-hydroxymethylfurfural (HMF) [7].

The wheat straw pulp then enters the decompression tank, where a rapid phase transition occurs. After expansion at $65^{\circ} \mathrm{C}$ in the decompression tank, the wheat straw pulp is directly fed to the biogas plant. The liquid effluent (recycled water) from the biogas plant was used as a reaction medium in the LHW-SE process. The ratio of wheat straw to recycled water was between 20:1 and 23:1. The daily continuous LHW-SE processing plant processes $2300-3800 \mathrm{~kg}$ of wheat straw using $100-160 \mathrm{~m}^{3}$ of recycled water.

\section{Chemical characterization}

The total solids (TS), volatile solids (VS), and ash contents were estimated according to the standard methods of the American Public Health Association [13] for preliminary characterization of the wheat straw, LHW-SE wheat straw, recycled water, and inocula used for biogas production. Fourier transform infrared (FT-IR) spectra of dry raw and LHW-SE pretreated wheat straw blades were obtained in the range of $400-4000 \mathrm{~cm}^{-1}$ on an FT-IR spectrophotometer (Bruker Vector 22 FT-IR) with a DTGS detector (Bruker, Germany) using a $\mathrm{KBr}$ disc 
containing $1 \%$ of the analyzed sample. The spectra were used to determine the changes in the functional groups that may have been caused by the pretreatment.

Size-exclusion chromatography (SEC) with an HPLC system was used to estimate the molecular mass of the water-soluble wheat straw products, compare them to the LHW-SE-processed pulp, and eliminate possible impurities from the recycled water. Water-soluble compounds from the wheat straw were isolated by maceration of $200 \mathrm{~g}$ of the ground wheat straw with $1000 \mathrm{~mL}$ of deionized water at room temperature for 7 days in the dark. The extract was then filtered through the Whatman filter paper to remove solids and evaporated under reduced pressure until dry.

The LHW-SE wheat straw pulp was centrifuged at $15,000 \times g$ for $10 \mathrm{~min}$ (Eppendorf Centrifuge 5804, Germany). The supernatant was collected and evaporated under reduced pressure until dry. The recycled water was also filtered through Whatman filter paper to remove some solid impurities and evaporated under reduced pressure until dry using a rotary evaporator. Each dry sample was dissolved in deionized water to obtain a concentration of $3 \mathrm{mg} \mathrm{mL}-1$ and then centrifuged at $2000 \times g$ for $5 \mathrm{~min}$. Each supernatant was filtered through a syringe filter with $0.45-\mu \mathrm{m}$ pore size (Costar, Corning, NY, USA) and degassed before analysis.

For the chromatographic separation, tandem columns consisting of a Hema-Bio 300 and Hema-Bio 100 (Tessek, Czech Republic) were used with a total resolving power of mass in the range of $8 \times 10^{4}-6 \times 10^{5} \mathrm{~g} \mathrm{~mol}^{-1}$. Deionized water was used as the eluent with flow rate of $0.6 \mathrm{~mL} \mathrm{~min}{ }^{-1}$. The injection volume was maintained at $100 \mu \mathrm{L}$. The molecular mass and its distribution among the samples was analyzed based on saccharides and phenolics using an HPLC system (Gilson, Poland) equipped with a GX-271 Liquid Handler, a UV/VIS-152 detector at a wavelength of $270 \mathrm{~nm}$, and a prepELS II evaporative light scattering detector. The temperature in the drift tube and the spray chamber were set as 45 and $10{ }^{\circ} \mathrm{C}$, respectively. The molecular mass of the samples was estimated carried out using a calibration curve of dextran standards $\left(7 \times 10^{4}, 2 \times 10^{5}, 5 \times 10^{5}\right.$ and $\left.1 \times 10^{6} \mathrm{~g} \mathrm{~mol}^{-1}\right)$ (Sigma-Aldrich, Germany). The results were analyzed using Trilution LC software v2.1.

Some of the volatile products in LHW-SE wheat straw were analyzed using GC-MS to verify that the LHWSE process was carried out under the conditions where the inhibitors of the methane fermentation process are absent. A pulp sample of LHW-SE wheat straw was centrifuged at $8000 \times g$ for $10 \mathrm{~min}$ to separate the straw blade fraction from the liquid suspension. The straw blades were dried at $37^{\circ} \mathrm{C}$ for 14 days and then extracted according to a previously described method [14]. The drying was performed under vacuum in vacuum dryer [Binder VD 23 (E2.1), Germany] to avoid potential microbial degradation. The dry wheat straw blades $(10.0 \mathrm{~g})$ were macerated with $200 \mathrm{~mL}$ of chloroform and then $200 \mathrm{~mL}$ of methanol for $72 \mathrm{~h}$ each at room temperature. Each extract was filtered through Whatman filter paper and evaporated under reduced pressure until dry.

GC-MS analysis was performed according to Rutkowski and Kubacki [15]. In brief, each collected extract was dissolved in its previous solvent and analyzed using an HP6890 gas chromatograph equipped with an HP5973 mass selective detector and HP- 5 ms column $(25 \mathrm{~m} \times 0.25 \mathrm{~mm}$ i.d., $0.25-\mu \mathrm{m}$ film thickness, crosslinked 5\% PH ME siloxane). The oven temperature program was $50-280{ }^{\circ} \mathrm{C}\left(4{ }^{\circ} \mathrm{C} \mathrm{min}{ }^{-1}\right)$ after an initial $1 \mathrm{~min}$ isothermal period. The final temperature was kept for $10 \mathrm{~min}$, and the flow rate of helium was $1 \mathrm{~mL} \mathrm{~min}^{-1}$. The inlet temperature was set at $260{ }^{\circ} \mathrm{C}$. The sample injection was done in split mode (1:5). The mass spectrometer was set at an ionizing voltage of $70 \mathrm{eV}$ with a mass range of $m / z 15-450$. Organic compounds were identified by comparing the mass spectra of the resolved components using NIST electronic-library search routines.

\section{Inocula and substrates}

LHW-SE wheat straw and raw wheat straw were used as the initial substrates in laboratory-scale biogas production. Both were stored for 14 days before use in the dark in sterile, anaerobic, dry conditions in high-density polyethylene (HDPE) bags. The inocula of the methane reactors were taken from the Koczała biogas plant (KB) (Poldanor S. A. Przechlewo Poland), which processes pig manure and corn silage. A positive control was obtained from the Strzelin agricultural biogas plant (SB) (Südzucker Polska S.A. Strzelin Poland), which processes beet pulp. Both samples of inocula were taken 4 days before the experiment and stored at $20-37{ }^{\circ} \mathrm{C}$ in polyethylene jars.

\section{Experimental design of LHW-SE pretreated wheat straw methanogenic potential}

Methanogenic potential tests were conducted similarly to Jabłoński et al. [16] with modifications. In the experiment 30 batch glass reactors with volumes of $1000 \mathrm{~mL}$ were used for measurements, five reactors for each experiment with dry wheat straw, LHW-SE pretreated wheat straw and without substrate as a reference sample. The reactors were loaded with inocula and operated for 28 days at a constant temperatures corresponding to the initial process carried out in the biogas plants which was $50{ }^{\circ} \mathrm{C}$ in $\mathrm{KB}$ and $39{ }^{\circ} \mathrm{C}$ in $\mathrm{SB}$. At the beginning, $500 \mathrm{~mL}$ of inoculum was added into each bioreactor. Half of the bioreactors received the inoculum from SB and the other 
half received inoculum from KB. Next, $100 \mathrm{~mL}$ of LHWSE wheat straw substrate was added to the first bioreactors containing SB inoculum (SB1). Similarly, $100 \mathrm{~mL}$ of LHW-SE wheat straw was added to bioreactors containing KB inoculum (KB1). For the third group of bioreactors with SB inoculum, $3.2 \mathrm{~g}$ of dry wheat straw and $100 \mathrm{~mL}$ of recycled water were added (SB2), and to the fourth group with $K B$ inoculum received $3.2 \mathrm{~g}$ of the dry wheat straw and $100 \mathrm{~mL}$ of recycled water (KB2). The fifth group with SB inoculum was used as control probes and received $100 \mathrm{~mL}$ of distilled water $(\mathrm{SBc})$. The sixth group of bioreactors with $\mathrm{KB}$ inoculum was the control mixtures and received $100 \mathrm{~mL}$ of distilled water $(\mathrm{KBC})$.

The mass of dry wheat straw added to the digestate was chosen so that the initial amount of VS from the substrates would be equal. The samples were stirred manually just before the gas measurements. The amount of biogas produced from the biomass was calculated as the difference between the production in the sample bottles and the production in the blank bottles (without the addition of substrate). PVC urine bags of $2000 \mathrm{~mL}$ (Cezal, Poland) with drain valves connected to the reactors outlets were used as to collect the biogas. The volumes of the biogas produced were measured at established time intervals after 1, 2, 3, 4, 5, 7, 10, 12, 14, 17, 21 and 28 days. The gas samples were taken from the collecting containers from the dedicated outlet port using a 100-mL PVC syringe. The same operation was repeated for each reactor. Biogas volumes were calculated for the standard state $(0.1 \mathrm{MPa})$.

\section{Koczała biogas plant basic characteristics}

$\mathrm{KB}$ contains three fermentation tanks with a capacity of approximately $3010 \mathrm{~m}^{3}$ and two digestion tanks with a capacity of approximately $3990 \mathrm{~m}^{3}$. The temperature of the biogas production in the digesters is $50{ }^{\circ} \mathrm{C}$, and the $\mathrm{pH}$ value is in the range of 7.45-7.60. The organic loading rate (OLR) [17] is $5.6 \mathrm{~kg} \mathrm{VS} /\left(\mathrm{m}^{3}\right.$ day), and the hydraulic retention time (HRT) is 31 days [17]. The maximum energy efficiency of the cogeneration engines (electric energy/thermal energy) of KB is $2126 / 2206 \mathrm{kWh}$, and the average methane concentration in the biogas is $51.5 \%$. The engine efficiency is assumed to be $40 \%$, and the methane energy value assumed to be $5.15 \mathrm{kWh} \mathrm{m}^{-3}$.

To theoretical biogas production was predicted as:

$$
V_{\mathrm{b}}=m_{\mathrm{dm}} \times V_{\text {teo }},
$$

where $V_{\mathrm{b}}$ is the theoretical biogas volume obtained from a substrate dry mass $\left[\mathrm{m}^{3}\right], m_{\mathrm{dm}}$ is the added mass of a particular substrate [t], and $V_{\text {teo }}$ is the assumed biogas volume, which should be obtained from the substrate's dry mass. $V_{\text {teo }}$ is obtained from experiments or published sources. The sum of each type of a substrate for which the theoretical biogas volume was calculated as:

$$
\sum V_{c}=V_{x}+V_{y}+V_{z}+V_{i}
$$

where $V_{x}, V_{y}, V_{z}$, and $V_{i}$ are theoretical biogas volumes calculated according to Eq. (1). Substrates used in the production of biogas were pig manure, corn silage and LWE-SE pretreated wheat straw. Recirculate counted as the fourth substrate.

\section{Energy balance calculation}

Theoretical average daily energy gain $[G]$ from LHW-SE pretreated WS was predicted as for period III:

$$
G=M \cdot V \cdot P \cdot N,
$$

where $[M]$ is an average mass input of LHW-SE pretreated WS; $[V]$ is an estimated actual LHW-SE pretreated WS biogas yield potential, $[P]$ is an average methane concentration in the biogas; [En] is the methane energy value.

The final electrical energy [Ee] and thermal energy [Et] value was estimated from the engine efficiency $[\mathrm{Ef}]$ :

$$
\begin{aligned}
& \mathrm{Ee}=G \cdot \mathrm{Ef} \\
& \mathrm{Et}=G-\mathrm{Ee} .
\end{aligned}
$$

\section{Statistical analysis}

Experimental data were statistically analyzed with a Student's $t$ test with statistical significance level 0.05 , implemented in Microsoft Office 2007.

\section{Results and discussion}

Raw, dry wheat straw (Triticum aestivum L.) was used as a material for pretreatment with LHW-SE to obtain a better substrate for biogas production. It was necessary to verify the laboratory results of the model process of biogas production with inoculum received from KB (Fig. 1) to assess the usefulness of the LHW-SE process in the biogas production process. HPLC, FT-IR, and GCMS analyses were conducted to explain the influence of the pretreatment process on the wheat straw structure.

\section{Chemical characterization of wheat straw, LHW-SE wheat straw, and inocula}

TS, ash, and VS amounts were estimated in the substrates, inocula, and recycled water (Table 1). Dry wheat straw contained high TS $(93.3 \% \mathrm{w} / \mathrm{w})$ and VS content $(90.4 \% \mathrm{w} / \mathrm{w})$, whereas the LHW-SE wheat straw had only $6.4 \%$ TS $(\mathrm{w} / \mathrm{w})$ and $5.4 \%$ VS $(\mathrm{w} / \mathrm{w})$. Both the wheat straw and LHW-SE wheat straw contained low amounts of ash (2.9 and $1.0 \% \mathrm{w} / \mathrm{w}$, respectively). The 


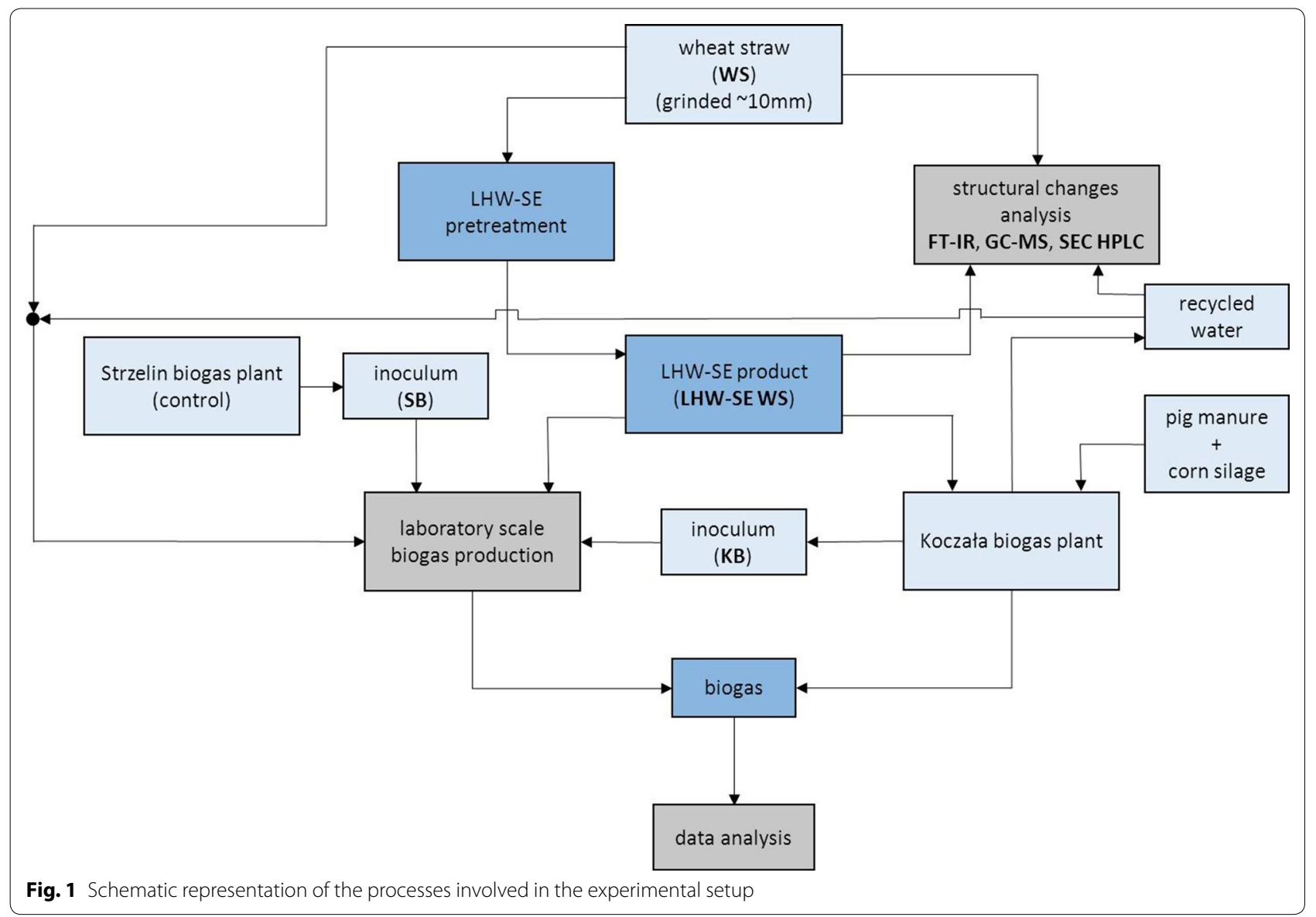

Table 1 TS, ash and VS used in the experiments of the biogas production

\begin{tabular}{lrrr}
\hline & TS (w/w\%) & Ash (w/w\%) & VS (w/w\%) \\
\hline Dry raw WS & $93.30 \pm 0.20$ & $2.94 \pm 0.07$ & $90.36 \pm 0.27$ \\
LHW-SE WS & $6.36 \pm 0.21$ & $0.98 \pm 0.02$ & $5.37 \pm 0.23$ \\
Recycled water & $3.39 \pm 0.01$ & $0.84 \pm 0.02$ & $2.55 \pm 0.03$ \\
$\begin{array}{l}\text { Inoculum of Koczała plant } \\
\text { (KB) }\end{array}$ & $4.50 \pm 0.04$ & $0.87 \pm 0.01$ & $3.62 \pm 0.05$ \\
$\begin{array}{l}\text { Inoculum of Strzelin plant } \\
\quad(S B)\end{array}$ & $3.14 \pm 0.02$ & $0.89 \pm 0.01$ & $2.25 \pm 0.03$ \\
& & &
\end{tabular}

Values are expressed as mean of five measurements $\pm S D$

Koczała inoculum used in the laboratory-scale experiments had $4.5 \%$ TS $(\mathrm{w} / \mathrm{w})$ and $3.6 \% \mathrm{VS}(\mathrm{w} / \mathrm{w})$, whereas the inoculum from the Strzelin plant used as a control contained less TS $(3.1 \% \mathrm{w} / \mathrm{w})$ and less VS $(2.3 \% \mathrm{w} / \mathrm{w})$. This difference might result from higher amount of the microorganism of $\mathrm{KB}$ or higher content of the undigested organic compounds. Both the KB inoculum and SB inoculum contained only $0.9 \%$ ash $(\mathrm{w} / \mathrm{w})$, while the recycled water was only $3.4 \%$ TS $(\mathrm{w} / \mathrm{w})$ and $0.8 \%$ ash $(\mathrm{w} / \mathrm{w})$. Recycled water contained $(2.6 \% \mathrm{w} / \mathrm{w})$ of VS. This may suggest a possible influence of using the recycled water as a medium in the $\mathrm{KB}$ biogas production process. To consider the possible impact on the results, recycled water was used in further analyses.

The finely ground samples of the wheat straw and LHW-SE wheat straw were analyzed using FT-IR spectroscopy (Fig. 2) to confirm that the pretreatment process caused structural changes in the plant material. The spectra indicated some similarities and differences. In the frequency region higher than $3000 \mathrm{~cm}^{-1}$, both spectra showed two wide bands. The first of them with a maximum occurred at $3272 \mathrm{~cm}^{-1}$ in both spectra, and the second bands occurred around 3094 and $3117 \mathrm{~cm}^{-1}$ for the wheat straw and for LHW-SE wheat straw, respectively. The second bands might correspond to the stretching vibrations $v(\mathrm{O}-\mathrm{H})$ of phenolic groups of lignocellulosic structures as well as hydroxyl bonds from other saccharides in the cell walls of the wheat straw [18, 19]. Interestingly, after the pretreatment of plant tissues, the second band became more intense, which might indicate a higher concentration of free - $\mathrm{OH}$ from other carbohydrate compounds. 


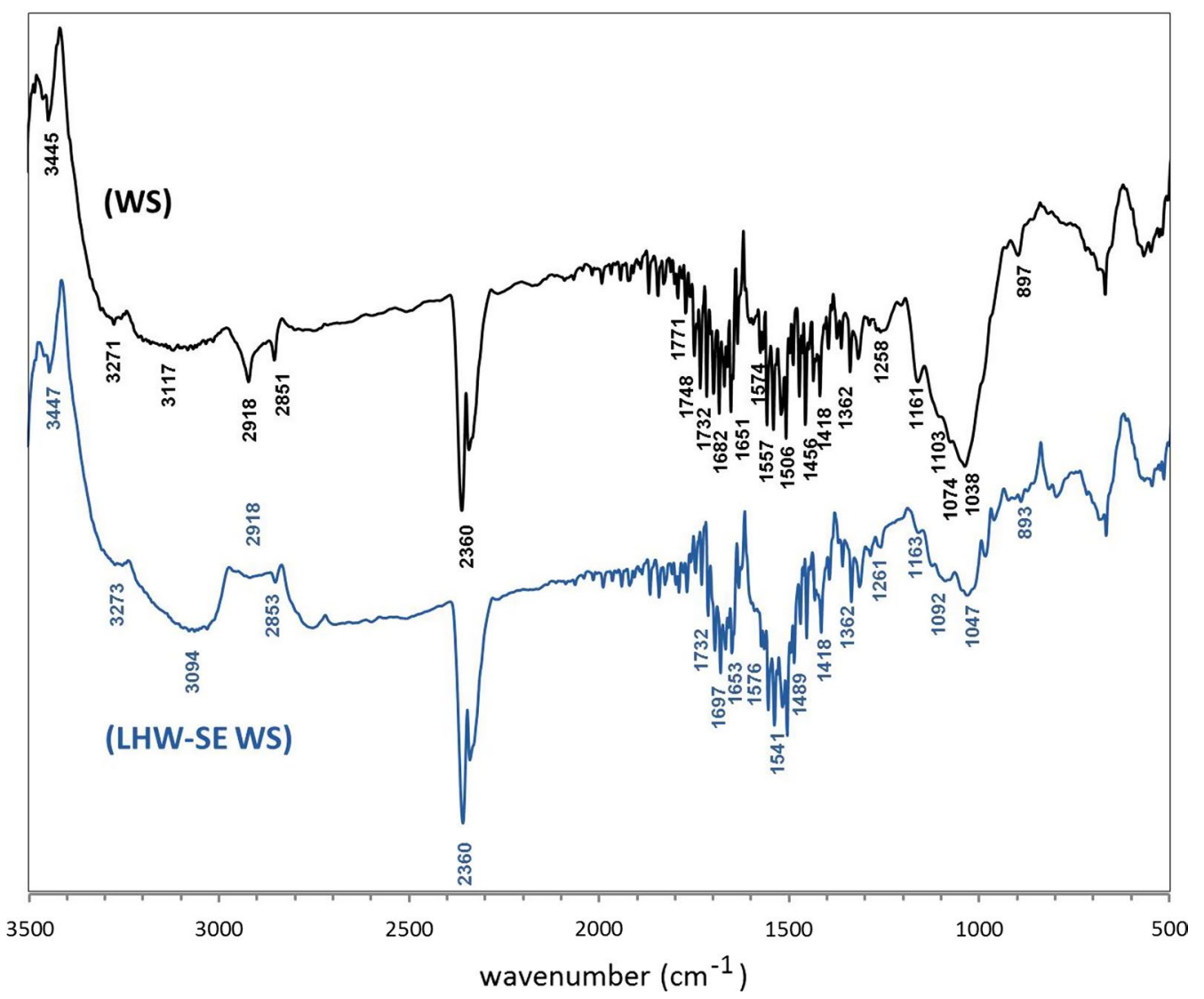

Fig. 2 FT-IR spectra of wheat straw (WS) and its pretreated solids product (LHW-SE WS)

Another two bands of high intensity with maximums at $2918 \mathrm{~cm}^{-1}$ and at $2852 \mathrm{~cm}^{-1}$ were observed in both spectra due to stretching vibrations $v(\mathrm{C}-\mathrm{H})$, but just the first of them was characteristic for $-\mathrm{CH}_{3}$ bonds, which are often present in the lignin network and as methyl esters of uronic acids in hemicelluloses. The second band confirmed the presence of $\left(-\mathrm{CH}_{2}-\right)$ fragments from saccharide units $[18,19]$. The stronger intensity of the first band in the wheat straw spectrum due to the symmetric stretching vibrations of $(\mathrm{C}-\mathrm{H})$ indicated a dominant amount of methyl bonds, which are probably present as the terminal ether bonds of the branched lignin structure [20]. These were almost not present in the LHW-SE wheat straw product. It might suggest that deesterification and perhaps even some delignification occurred during the pretreatment process [18].

Two sharp peaks centered around $2360 \mathrm{~cm}^{-1}$ were assigned to the characteristic vibration of the aromatic rings present in the lignocellulosic material [21]. In the range of $1800-2000 \mathrm{~cm}^{-1}$, a group of less intense signals was observed in both spectra. These peaks were overtones of aromatic rings, confirming the presence of a rich phenolic lignin structures. Guaiacyl-syringyl lignins
(GS) in grass (including cereals) contain major amounts of structural elements derived from $p$-coumaryl alcohol, coniferyl alcohol, and sinapyl alcohol [20], as well as some polyphenolic acids as ferulic and $p$-coumaric acids $[22,23]$. They create lignocellulosic macromolecular conglomerates with cellulose and with hemicelluloses full of carboxylic functional groups in esterified and free forms.

The presence of $(\mathrm{C}=\mathrm{O})$ bonds of the esterified types $[19,24,25]$ were observed in both spectra as stretching vibration signals at 1748 and $1732 \mathrm{~cm}^{-1}$, but they were less intense in the LHW-SE wheat straw spectrum. In the contrast, a group of signals in the range of 1697$1634 \mathrm{~cm}^{-1}$ was more intense in the spectrum of the pretreated liquor product compared to the untreated wheat straw. This region typically shows stretching vibration signals of carbonyl groups from carboxylic bonds that are not esterified [19, 24, 25]. An additional band of the symmetric $v(\mathrm{C}=\mathrm{O})$ stretching vibrations with a maximum at $1418 \mathrm{~cm}^{-1}$ was detected in both spectra. Another group of peaks in the range of $1580-1480 \mathrm{~cm}^{-1}$ was ascribed to the skeletal interactions of aromatic rings in lignin [26]. It became more intense after pretreatment of the wheat straw with the LHW-SE process. 
In summary, the characteristic features of delignification might be the increase in intensity of the general carbonyl absorbances in the range of 1770-1630 and around $1260 \mathrm{~cm}^{-1}$ [26].

Further bands indicated the presence of $(\mathrm{C}-\mathrm{H})$ bonds located at 1456 and $1373 \mathrm{~cm}^{-1}$, which were responsible for asymmetric and symmetric stretching interactions, respectively [23]. Moreover, the $1456 / 1506 \mathrm{~cm}^{-1}$ ratio was representative of the ratio of syringyl to guaiacyl (S/G) in lignin [27]. The lower S/G ratio in the LHW-SE wheat straw in comparison to the untreated wheat straw might suggest a loss of S monomers in the process of delignification. The other peaks might confirm this theory, where there was a less intense band for the $v(\mathrm{C}-\mathrm{O}-\mathrm{C})$ stretching vibrations typical for the syringyl rings at $1317 \mathrm{~cm}^{-1}$ in the spectrum of the pretreated liquor product. The band of the $v(\mathrm{C}-\mathrm{O}-\mathrm{C})$ stretching vibrations of the guaiacyl rings detected at $1261 \mathrm{~cm}^{-1}$ was shifted to $1258 \mathrm{~cm}^{-1}$ [23]. There was also lower intensity for the band of the $v(\mathrm{C}-\mathrm{O}-\mathrm{C})$ stretching interactions of $p$-coumaric ester groups typical for $p$-hydroxyphenyl guaiacyl and syringal (GSH) lignins detected at $1163 \mathrm{~cm}^{-1}$ [28].

FT-IR bands indicating the presence of polysaccharides were found at about 1074, 1038 and $1103 \mathrm{~cm}^{-1}[v(\mathrm{C}-$ $\mathrm{O}-\mathrm{C}), v(\mathrm{C}-\mathrm{OH})$, and $v(\mathrm{C}-\mathrm{C})$ of the saccharide rings], which were derived from cellulose and hemicelluloses $[19,29,30]$. After the LHW-SE process, the intensity of the signals in this region significantly decreased and shifted. In the spectrum of the LHW-SE wheat straw, signals were detected with maximums at 1126, 1092-1080, and $1047-1016 \mathrm{~cm}^{-1}[v(\mathrm{C}-\mathrm{O}-\mathrm{C}), v(\mathrm{C}-\mathrm{OH})$, and $v(\mathrm{C}-\mathrm{C})$ of the saccharide rings]. This change might suggest a degradation of the polysaccharide network to shorter saccharide chains and monosaccharides.

In the anomeric regions of the FT-IR spectra of untreated wheat straw and LHW-SE wheat straw, the clear bands with low intensity at $897-893 \mathrm{~cm}^{-1}$ were attributed to the $\beta$-glycosidic linkages $(1 \rightarrow 4)$, which are especially characteristic of cellulose structure. For the $\alpha$ form, the bands typically occur at $837-840 \mathrm{~cm}^{-1}[30,31]$. The band of $\beta$ bonds was much smaller in the spectrum of the pretreated liquor product. There might be few reasons, i.e. a weaker bonding dynamics of cellulose fibers due to the violation of the ordered crystal structure in the pretreatment process. Another reason of the lower intensity of this band might be the degradation of $\beta$-glycosidic bonds with polyphenolic compounds, where some loss of polyphenols in the pretreated liquor product by SEC analysis is confirmed.

SEC analysis of the water-soluble components was also performed using HPLC (Fig. 3a-c). Using a dual detection system comprising UV-Vis and electrospray light scattering (ELS) detectors, it was possible to detect some compounds with and without chromophore groups in their structures; i.e., polyphenolic glycoconjugates and pure saccharides. The water-soluble extracts of both wheat straw and LHW-SE wheat straw contained three fractions with polyphenolic-polysaccharide or oligosaccharide nature (Fig. 3, Table 2). SEC analysis of the wheat straw extract indicated peaks with molecular masses $(M \mathrm{p})$ of $\sim 1500 \times 10^{3} \mathrm{~g} \mathrm{~mol}^{-1}(22.0 \%$ of the analyzed mixture), $\sim 30 \times 10^{3} \mathrm{~g} \mathrm{~mol}^{-1}(39.1 \%)$, and $\sim 1-10 \times 10^{3} \mathrm{~g} \mathrm{~mol}^{-1}(37.7 \%)$. In the chromatogram of the LHW-SE wheat straw extract, peaks with the following $M \mathrm{p}$ were detected: $\sim 2300 \times 10^{3} \mathrm{~g} \mathrm{~mol}^{-1}(7.9 \%)$, $\sim 30 \times 10^{3} \mathrm{~g} \mathrm{~mol}^{-1}(16.3 \%)$, and $\sim 0.2-1 \times 10^{3} \mathrm{~g} \mathrm{~mol}^{-1}$. The last value is notable in that it represents as much as $75.6 \%$ of the analyzed mixture. Both chromatograms suggested a conjugate nature of the separated fractions, where saccharides were detected with similar retention time to polyphenolics, but the value was lower for the LHW-SE wheat straw. The water-soluble fractions of LHW-SE wheat straw contained much less polyphenolic compounds, and the average molecular mass of the last one suggested oligo- or even monosaccharide nature.

After the pretreatment process the peak of monosaccharides with the longest retention time (Fig. 3a) significantly increased. Two peaks of macromolecular structures decreased, what is in the SEC chromatogram (Fig. 3b) well observed. In conclusion, the (LHW-SE WS) product is containing much more low molecular weight saccharides, which are the best absorbed carbon source for the microorganisms, to growth and development, what is inseparable from the increase in the productivity of biogas formation.

It was also necessary to check for possible impurities in the recycled water used in the pretreatment process. The results (Table 2) indicated that the use of compost water obtained from the post-fermentation process may have some influence on LHW-SE pretreatment process and methanogenesis in biogas plant. Small amounts of polysaccharides and polyphenolics such as glycoconjugates were found, but there were no monosaccharides. This suggests that the recycled water might be as good as tap water. In summary, the SEC analysis confirmed that the LHW-SE process leads to the hydrolysis of the polysaccharides contained in wheat straw into oligo- and monosaccharides.

Literature data indicate that inhibitors of the methanogenesis process such as furfural and its derivatives (i.e., HMF) might be produced in the LHW-SE pretreatment process [17]. GC-MS analysis was performed on extracts of the LHW-SE wheat straw, which were obtained using chloroform (extracted mass $4.7 \% \mathrm{w} / \mathrm{w}$ ) and methanol (extracted mass $12.2 \% \mathrm{w} / \mathrm{w}$ ). Concentrations of chloroform and methanol extracts used in GC-MS analysis 

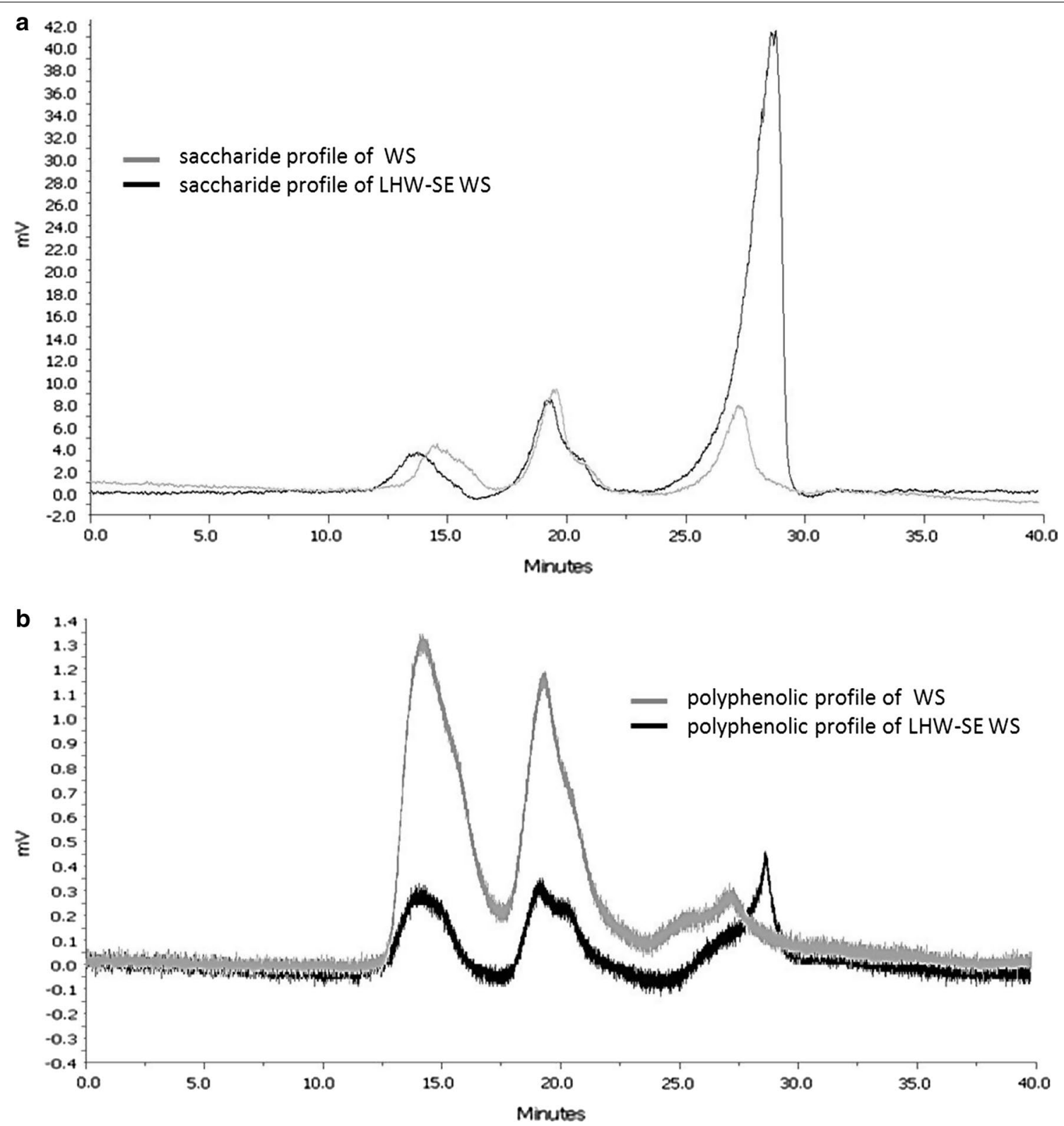

Fig. 3 Size exclusion chromatography (SEC) analysis of water-soluble compounds. a Saccharide profile of wheat straw (WS) and of its pretreated liquor product (LHW-SEWS), identified by evaporative light scattering (ELS) detection method; b polyphenolic profile of wheat straw (WS) and of its pretreated liquor product (LHW-SE WS), where they were detected using UV-Vis detection system $(\lambda=270 \mathrm{~nm})$

were 0.0237 and $0.0610 \mathrm{~g} \mathrm{~mL}^{-1}$. A group of compounds were detected (Table 3), and some of them may have a positive influence on the methanogenesis process, such as carboxylic acids. These compounds are intermediate substrates and lead to the formation of acetate, carbon dioxide, and hydrogen, which are a crucial substrates for methanogenic archaea. These substrates may affect the overall high amounts of methane produce within the process. No common methanogenesis inhibitors were found [32] including furfural and its derivatives. Extracts of pretreated wheat straw solids did not show any typical inhibitors of the methane fermentation process, such as furfural and HMF, which indicates that the process was carried out under appropriate conditions, although there is still room for improvement. As we do not detect inhibitory compounds (ex. furfural) it should be possible to increase SF (severity factor) of the LHW-SE process [7]. 
Table 2 Results of the water-soluble components of the LHW-SE WS pulp, and recycled water SEC HPLC analysis

\begin{tabular}{|c|c|c|c|c|c|c|c|c|}
\hline \multirow[t]{3}{*}{ Fraction no. } & \multicolumn{4}{|l|}{ (WS) } & \multicolumn{4}{|l|}{ (LHW-SE WS) } \\
\hline & \multirow{2}{*}{$\begin{array}{l}\text { Average } \\
M p \times 10^{3} \mathrm{~g} \mathrm{~mol}^{-1}\end{array}$} & \multicolumn{3}{|l|}{$\%$} & \multirow{2}{*}{$\begin{array}{l}\text { Average } M p \times 10^{3} \\
\mathrm{~g} \mathrm{~mol}^{-1}\end{array}$} & \multicolumn{3}{|l|}{$\%$} \\
\hline & & Polyphenolic part & Saccharide part & $\sum$ & & Polyphenolic part & Saccharide part & $\sum$ \\
\hline 1 & $\sim 1500$ & 5.6 & 16.4 & 22.0 & $\sim 2300$ & 0.4 & 7.5 & 7.9 \\
\hline 2 & $\sim 30$ & 3.5 & 35.6 & 39.1 & $\sim 30$ & 0.5 & 15.8 & 16.3 \\
\hline \multirow[t]{2}{*}{3} & $\sim 1-10$ & 6.6 & 31.1 & 37.7 & $\sim 0.2-1$ & 0.5 & 75.1 & 75.6 \\
\hline & & & & 98.8 & & & & 99.8 \\
\hline \multicolumn{9}{|c|}{ Impurities from recycled water } \\
\hline 4 & $\sim 1500$ & 0.12 & 0.58 & 0.72 & $\sim 1500$ & 0.03 & 0.09 & 0.12 \\
\hline \multirow[t]{2}{*}{5} & $\sim 160$ & 0.08 & 0.42 & 0.48 & $\sim 160$ & 0.02 & 0.06 & 0.08 \\
\hline & & & & 1.20 & & & & 0.20 \\
\hline
\end{tabular}

Table 3 GC-MS analysis of the LHW-SE WS chloroform extract and methanol extract compounds

\begin{tabular}{|c|c|c|c|}
\hline Signal no. & $\begin{array}{l}\text { Retention time } \\
(\min )\end{array}$ & Compound name & Area (\%) \\
\hline & & $\begin{array}{l}\text { Compounds in the chloro- } \\
\text { form extract }\end{array}$ & \\
\hline 1 & 19.98 & Dodecanoic acid & 34.41 \\
\hline 2 & 22.04 & 2-Pentadecanol & 1.98 \\
\hline 3 & 23.89 & Hexadecanoic acid & 4.63 \\
\hline 4 & 27.90 & Hexanedioic acid & 6.07 \\
\hline \multirow[t]{2}{*}{5} & 31.09 & $\begin{array}{l}\text { 1,2-Benzenedicarboxylic } \\
\text { acid }\end{array}$ & 13.17 \\
\hline & & $\begin{array}{l}\text { Compounds in the } \\
\text { methanol extract }\end{array}$ & \\
\hline 1 & 5.41 & Acetic acid & 35.14 \\
\hline 2 & 8.67 & Propionic acid & 2.61 \\
\hline 3 & 9.36 & Butanoic acid & 3.07 \\
\hline 4 & 12.55 & Hexanoic acid & 5.05 \\
\hline 5 & 20.44 & Ethylene & 0.84 \\
\hline 6 & 22.56 & Pentadecanoic acid & 2.98 \\
\hline 7 & 23.90 & Hexadecanoic acid & 4.92 \\
\hline 8 & 24.10 & $\begin{array}{l}\text { 1,2-Benzenedicarboxylic } \\
\text { acid }\end{array}$ & 1.52 \\
\hline 9 & 24.34 & $\begin{array}{l}\text { 9,12-Octadecadienoic } \\
\text { acid }(Z, Z)\end{array}$ & 6.73 \\
\hline 10 & 24.51 & $\begin{array}{l}9,12,15 \text {-Octadecatrie- } \\
\text { noic acid }\end{array}$ & 0.96 \\
\hline 11 & 25.62 & Oleic acid & 15.80 \\
\hline
\end{tabular}

\section{Laboratory-scale of biogas from LHW-SE wheat straw}

The influence of the LHW-SE pretreatment of wheat straw was evaluated by biological tests of the methanogenic potential using two different methanogenic consortia: the inocula from the methane reactor of $\mathrm{KB}$ and $\mathrm{SB}$. The SB inoculum was used as a control to see whether the different compositions of microorganisms have a significant effect on the amount of gas produced from the processed straw. The cumulative daily biogas production is presented in Fig. 4.

Experiments carried out in a laboratory. Data expressed in the cumulative average daily production after deduction of the control samples C.

The data show that the biogas production increased when using pretreated wheat straw as a raw material in comparison to raw wheat straw. The LHW-SE pretreatment improved the wheat straw decomposition and the methane yield by $24 \%$ when using inoculum from KB and by $35 \%$ when using inoculum from SB. Notably, the biogas production with the methanogenic consortium from SB was significantly higher than that obtained with the KB consortium. This may result from differences the in anaerobic digestion temperature, which was $50{ }^{\circ} \mathrm{C}$ for $\mathrm{KB}$ and $39^{\circ} \mathrm{C}$ for $\mathrm{SB}$. These temperatures could affect the species composition. Methanogenic species have a range spectrum of metabolic capabilities [33]. Thus, modification of the consortium could potentially be a good target for further increasing the process efficiency. Independently of the methanogenic consortium, the higher biogas yield after pretreatment suggests a change in the structure of the wheat straw, which contributed to the accelerated and increased production of biogas.

\section{Biogas and LHW-SE plants processing data}

To estimate the actual impact of the LHW-SE pretreatment on methane fermentation in a biogas plant, the theoretical and real biogas yields were compared. Processing data from the KB biogas plant are presented for a span of over 5 years, including the averages of 10 days of sampling and standard deviations. The data presented in Figs. 5 and 6 include the average biogas yield in reference 


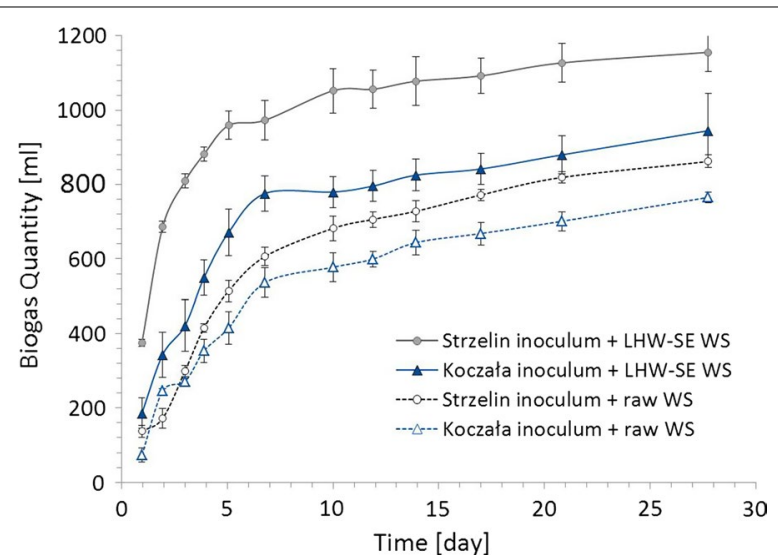

Fig. 4 Biogas yield potential measurement of wheat straw (WS) and its pretreated product (LHW-SE WS)

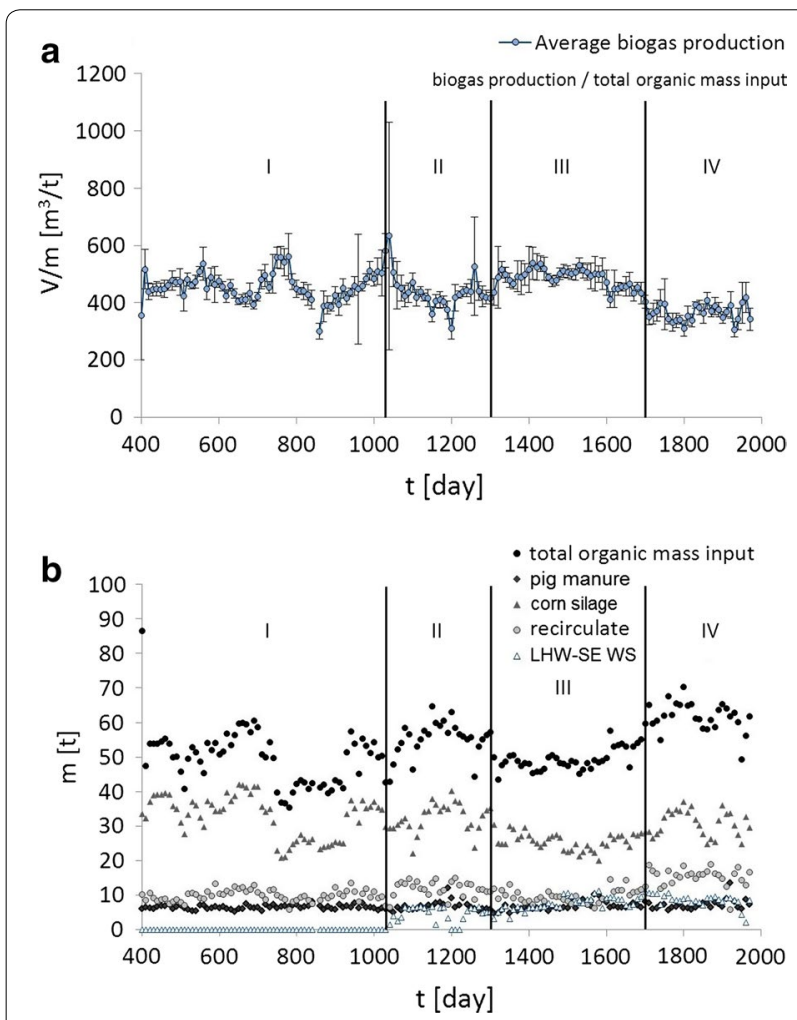

Fig. 5 Processing data in Koczała biogas plant (KB) presented in the span of over 5 years. $\mathbf{a}$ The average biogas production on the total organic dry mass input. b Raw materials contribution in the total organic dry mass

to the total organic dry mass (TOC) (Fig. 5a), the type and quantity of organic mass input (Fig. $5 \mathrm{~b}$ ), and actual and theoretically estimated biogas yield (Fig. 6).
The theoretical biogas yield was estimated by assigning a methanogenic potential to each independent substrate (Table 4). Observations started on the 400th day because many malfunctions occurred and the methanogenesis was not stable in the first year of operation which mainly resulted from pump failures, unsealing of high-pressure installations and clogging of pipes. The LHW-SE pretreatment plant was launched on the 1040th day, when observation period I ends and period II begins. During period I, a major malfunction occurred on the 750th day and lasted 200 days, during which the biogas yield dropped by half. This period enabled confirmation of the correlation between the theoretical biogas yield (for each biomass substrate except the pretreated wheat straw) and the real biogas yield. During period II, the LHW-SE pretreatment plant for wheat straw began operation and was stabilized.

The biogas plant aims for an average biogas yield of $\approx 500 \mathrm{~m}^{3} \mathrm{t}_{\mathrm{dm}}^{-1}$ in reference to TOC in methane fermentation, except in periods when the plant is overfed (Fig. 5a). Overfeeding occurs due to organic overload [16], when the amount of organic matter fed to the biogas plant exceeds the total degradation capacity of the microbes to produce biogas. In this case, Fig. $5 \mathrm{~b}$ shows that the ratio of substrates changes because of the corn silage input increases together with the TOC. Despite the high input, the biogas yield drops due to overfeeding.

Figure 6 shows that the highest and most stable biogas production occurs in observation period III (between the 1300th and 1700th days), despite the lowest overall TOC and significant drop in corn silage input. The drop was slightly compensated by increasing the addition of LHWSE wheat straw. The theoretical and real biogas yield in period III (Fig. 6) shows the actual long-term biogas yield was higher than the theoretically estimated yield for the first time, despite the low TOC and corn silage input. The only parameters that changed significantly during this time were the quantity and quality of the pretreated wheat straw. It was concluded that the laboratory data on the theoretical methanogenic potential underestimated the actual performance. The biogas potential estimated in the experiments was $350 \mathrm{~m}^{3} \mathrm{t}_{\mathrm{dm}}^{-1}$ of biogas yield, but the value estimated from the theoretical and actual yield revealed $600 \mathrm{~m}^{3} \mathrm{t}_{\mathrm{dm}}^{-1}$ of biogas yield from LHW-SE pretreated wheat straw. The difference between the laboratory-estimated and experimentally measured methanogenic potential of wheat straw may have resulted from the positive impact of the different substrates used in codigestion [4].

Observation period IV includes an attempt to increase the biogas yield by increasing the input of corn silage and 


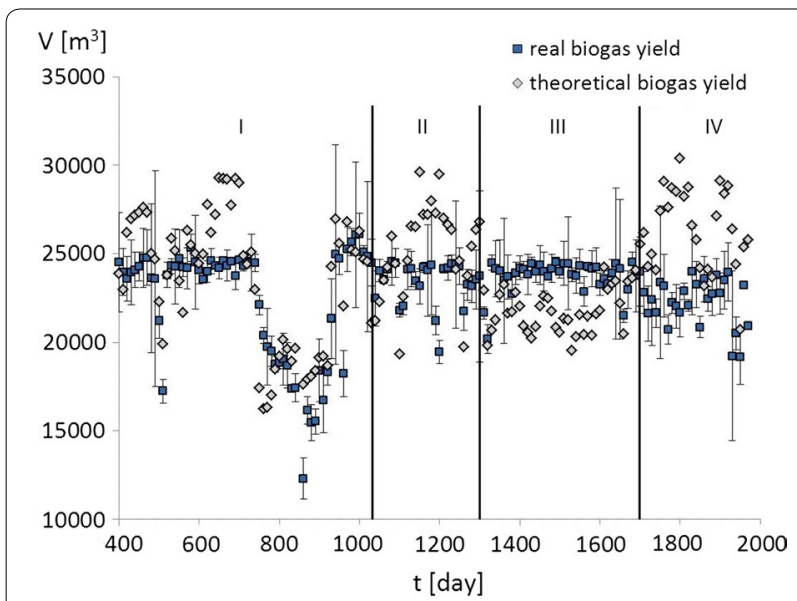

Fig. 6 Correlation of real and theoretical biogas yield charts in Koczała plant over 1570 days of work

Table 4 The average biogas yield produced from the dry organic mass

\begin{tabular}{lc}
\hline Raw material & Theoretical biogas yield $\left(\mathbf{m}^{\mathbf{3}} \mathbf{t}_{\mathbf{d m}}^{\mathbf{- 1}}\right)$ \\
\hline Pig slurry & $320^{\mathrm{a}}$ \\
Corn silage & $610^{\mathrm{b}}$ \\
Recirculate & $150^{\mathrm{c}}$ \\
LHW-SEWS & $350^{c} / 600^{\mathrm{d}}$ \\
\hline
\end{tabular}

${ }^{a} \mathrm{~m}^{3} \mathrm{t}_{\mathrm{dm}}^{-1}$ of biogas yield from the dry organic mass depending on the literature data [4]

${ }^{b} \mathrm{~m}^{3} \mathrm{t}_{\mathrm{dm}}^{-1}$ of biogas yield calculated, based on the methanogenic potential of recirculate measured in the experiments in the laboratory scale

c $350 \mathrm{~m}^{3} \mathrm{t}_{\mathrm{dm}}^{-1}$ of biogas yield calculated, based on the methanogenic potential of LHW-SE WS according to the laboratory data, measured in the experiments in the laboratory scale

d $600 \mathrm{~m}^{3} \mathrm{t}_{\mathrm{dm}}^{-1}$ of biogas yield obtained according to the biogas plant data

recirculated mass. However, the attempt failed and ended up in overfeed conditions. The biogas yield sudden decreases on the 1700th day, which lasted 270 days until the end of the experiment. The point with the biggest deviation occurred on day 1040, which corresponds to the launch of the LHWSE pretreatment plant. The big deviation appeared because the digesters were not fed such for a few days before the launch. The big deviations on the 950th, 1260th, and 1320th days resulted from malfunctions in the biogas plant which mainly resulted from pump failures, unsealing of high-pressure installations and clogging of pipes.

In period III, the biogas yield of $600 \mathrm{~m}^{3} \mathrm{t}_{\mathrm{dm}}^{-1}$ corresponds to the corn silage methanogenic potential. This observation suggests that the LHW-SE wheat straw could be a good substitute for corn silage, which is easily accessible and a cheap waste biomass material with the same methanogenic potential.
Table 5 Average daily energy consumption in liquid hot water-steam explosion plant

\begin{tabular}{lclc}
\hline Energy type & LHW-SE (kWh) & Mill (kWh) & Overall (kWh) \\
\hline Electrical & 568 & 59 & 627 \\
Thermal & 10,339 & - & 10,339 \\
$\Sigma$ & 10,907 & 59 & 10,966 \\
\hline
\end{tabular}

Average for 750 days of operation excluding malfunctions since LHW-SE launch

Theoretical profitability of LHW-SE pretreatment process

Theoretical profitability was estimated based on the average plant energy consumption, data presented in Table 5 . Complementing them with LHW-SE pretreated WS methanogenic potential, data from Table 4 and the input and output data from Figs. 5 and 6, we estimated theoretical net energy profit presented in Table 6.

Although the theoretical profit seems to be large, unfortunately its potential has not been exploited. This was due to the continuous failure of the installation, the lack of potential heat energy buyers and the unstable process of methanogenesis in the biogas plant caused by overfeeding. That is why sometimes gross profit from using this type of plant was negative.

\section{Conclusions}

This study confirmed the hypothesis that the LHW-SE combined pretreatment process increases the bioavailability of carbohydrates in wheat straw for methane fermentation microorganism consortia. The KB inoculum fed with pretreated wheat straw increased the methane yield by $24 \%$ in comparison to raw straw. Surprisingly, the SB inoculum produced biogas more efficiently, with $34 \%$ higher performance in comparison to the $\mathrm{KB}$ inoculum. The data obtained from the KB biogas plant before and after using the LHW-SE pretreated wheat straw suggest that it is good to diversify the substrates, which give similar biogas yields to corn silage. According to Jabłoński et al. [33], continuous-flow reactors are favored in one-step pretreatment processes because of their continuous procedure. However, they lead to major drawbacks of relatively low substrate concentrations and high energy demand for processing (due to pressure and heating in our case). The batch autoclave has an advantage because no substrate processing is necessary, and high

Table 6 Average theoretical daily energy net profitability from liquid hot water-steam explosion plant

\begin{tabular}{ll}
\hline Energy type & LHW-SE (kWh) \\
\hline Electrical & 15,300 \\
Thermal & 13,500 \\
$\Sigma$ & 28,800 \\
\hline
\end{tabular}


solid-to-water ratios can be used. However, the decomposition of sugars can lead to undesired degradation products (furfural, HMF), insufficient lignin removal, and poor enzymatic digestibility. Rogalinski [34] proposed using a fixed-bed reactor that minimizes the disadvantages and enhances benefits of these two types of reactors. Combined processes of liquid hot water (LHW) and steam explosion (SE) could be considered as a good option for the green pretreatment of biomass. However, a new kind of plant should be developed while taking into account the minimization of heat and processing costs, as well as undesired degradation products with higher lignin degradation rates and enzymatic availability. The latest research indicates that the hydrothermal pretreatment of lignocellulosic biomass continues to be developed [35], and its profitability could still be increased.

\section{Abbreviations}

ELS: evaporative light scattering; FT-IR: Fourier transform infrared spectroscopy; KB: the Koczała biogas plant; LHW-SE: liquid hot water-steam explosion; SB: Strzelin biogas plant; SEC: size exclusion chromatography; TOC: total organic dry mass; TS: the total solids; VS: volatile solids; WS: wheat straw.

\section{Authors' contributions}

MG, SJ, RG and M $\mathrm{t}$ conceived the work. MG, IP-G and M $\mathrm{t}$ wrote the manuscript. IP-G and MG performed the FT-IR analysis and description. IP-G and RZ performed the SEC-HPLC analysis and description. MG, AW and PR performed the GC-MS analysis. MG and SJ evaluated methanogenic potential. All authors read and approved the final manuscript.

\section{Author details}

${ }^{1}$ Department of Biotransformation, Faculty of Biotechnology, University of Wrocław, Fryderyka Joliot-Curie 14a, 50-383 Wrocław, Poland. ${ }^{2}$ Department of Organic and Pharmaceutical Technology, Faculty of Chemistry, Wrocław University of Science and Technology, Wybrzeże Wyspiańskiego 27, 50-370 Wrocław, Poland. ${ }^{3}$ Department of Polymer and Carbonaceous Materials, Faculty of Chemistry, Wrocław University of Science and Technology, Gdańska 7/9, 50-344 Wrocław, Poland.

\section{Acknowledgements}

The authors would like to thank to the POLDANOR S.A. company, especially to Mr. Grzegorz Brodziak, Mr. Łukasz Majewski, and Mr. Beny Laursen for their assistance and the use of their facility. We also would like to thank to the Südzucker Polska S.A. company for accessing the inoculum from Strzelin biogas plant used in the experiments. Dr. Katarzyna Pstrowska and Dr. Marek Kułażyński are acknowledged for their assistance in the FT-IR analysis.

\section{Competing interests}

The authors declare that they have no competing interests.

\section{Availability of supporting data}

All data generated or analyzed during this study are included in this published article.

\section{Funding}

This work was financially supported by Wroclaw Center of Biotechnology, program: The Leading National Research Center (KNOW) for years 2014-2018; by Polish National Centre for Research and Development (NCBiR) as a part of a project KompUtyl (BIOSTRATEG2/298357/8/NCBR/2016); and by statutory activity subsidies from Polish Ministry of Science and Higher Education for the Faculty of Chemistry of Wrocław University of Science and Technology. Part of analyzes was made on the HPLC system purchased by the Project "WroVasc-Integrated Cardiovascular Center", co-financed by the European Regional Development Fund, within Innovative Economy Operational
Program, 2007-2013 realized in Regional Specialist Hospital, Research and Development Center in Wroclaw. "European Funds—for the development of innovative economy".

\section{Publisher's Note}

Springer Nature remains neutral with regard to jurisdictional claims in published maps and institutional affiliations.

Received: 15 July 2017 Accepted: 3 October 2017

Published online: 09 November 2017

\section{References}

1. Darmani A, Rickne A, Hidalgo A, Arvidsson N. When outcomes are the reflection of the analysis criteria: a review of the tradable green certificate assessments. Renew Sustain Energy Rev. 2016;62:372-81.

2. Jabłoński SJ, Biernacki P, Steinigeweg S, Lukaszewicz M. Continuous mesophilic anaerobic digestion of manure and rape oilcake-experimental and modelling study. Waste Manag. 2015;35:105-10.

3. Jabłoński S, Krasowska A, Januszewicz J, Vogt A, Łukaszewicz M. Cascade reactor system for methanogenic fermentation. Chall Mod Technol. 2011;2:37-41

4. Szlachta J, Fugol M, Prask H, Kordasz L, Luberański A, Kułażyński M. Analiza i przygotowanie wsadu zawierającego organiczne odpady rolnicze, hodowlane i przemysłowe oraz odchody. Wrocław: Modelowe Kompleksy Agroenergetyczne; 2014.

5. Montgomery L, Bochmann G. Pretreatment of feedstock for enhanced biogas production. IEA Bioenergy. 2014. Available at: http://www.builda-biogas-plant.com/PDF/pretreatment_iea2014.pdf. Accessed 30 June 2017

6. Madej A. Straw balance in Poland in the years 2010-2014 and forecast to the year 2030. Stow Ekon Rol i Agrobiznesu Rocz Nauk. 2014;18/1:163-8

7. Hendriks ATWM, Zeeman G. Pretreatments to enhance the digestibility of lignocellulosic biomass. Bioresour Technol. 2009;100:10-8.

8. Shaw MD, Karunakaran C, Tabil LG. Physicochemical characteristics of densified untreated and steam exploded poplar wood and wheat straw grinds. Biosyst Eng. 2009;103:198-207.

9. Alvira P, Negro MJ, Ballesteros I, González A, Ballesteros M. Steam explosion for wheat straw pretreatment for sugars production. Bioethanol. 2016;2:66-75. http://www.degruyter.com/view/j/bioeth.2015.2.issue-1/ bioeth-2016-0003/bioeth-2016-0003.xml.

10. Shafiei M, Kabir MM, Zilouei H, Sárvári Horváth I, Karimi K. Technoeconomical study of biogas production improved by steam explosion pretreatment. Bioresour Technol. 2013;148:53-60.

11. Janzon R, Schütt F, Oldenburg S, Fischer E, Körner I, Saake B. Steam pretreatment of spruce forest residues: optimal conditions for biogas production and enzymatic hydrolysis. Carbohydr Polym. Elsevier Ltd.; 2014;100:202-10. http://dx.doi.org/10.1016/j.carbpol.2013.04.093.

12. Kumar P, Barrett DM, Delwiche MJ, Stroeve P. Methods for pretreatment of lignocellulosic biomass for efficient hydrolysis and biofuel production. Ind Eng Chem Res. 2009;48:3713-29.

13. APHA/AWWA/WEF. Standard methods for the examination of water and wastewater. 20th edn. Washington, 1999. Available at: http://www. standardmethods.org. Accessed 30 June 2017.

14. Durmaz G, Gökmen V. Determination of 5-hydroxymethyl-2-furfural and 2 -furfural in oils as indicators of heat pre-treatment. Food Chem. 2010;123:912-6.

15. Rutkowski P, Kubacki A. Influence of polystyrene addition to cellulose on chemical structure and properties of bio-oil obtained during pyrolysis. Energy Convers Manag. 2006:47:716-31.

16. Jabłoński S, Kułażynski M, Sikora I, Łukaszewicz M. The influence of different pretreatment methods on biogas production from Jatropha curcas oil cake. J Environ Manage. 2016;203:714-9.

17. Drosg B. Process monitoring in biogas plants. IEA Bioenergy. 2013. Available at: http://www.iea-biogas.net/files/daten-redaktion/download/Technical Brochures/Technical Brochure process_montoring.pdf. Accessed 30 June 2017. 
18. Sun RC, Tomkinson J. Comparative study of lignins isolated by alkali and ultrasound-assisted alkali extractions from wheat straw. Ultrason Sonochem. 2002;9:85-93.

19. Kačuráková M, Capek P, Sasinková V, Wellner N, Ebringerová A. FT-IR study of plant cell wall model compounds: pectic polysaccharides and hemicelluloses. Carbohydr Polym. 2000;43:195-203.

20. Upton BM, Kasko AM. Strategies for the conversion of lignin to high-value polymeric materials: review and perspective. Chem Rev. 2016;116:2275-306.

21. Ruiz HA, Ruzene DS, Silva DP, Macieira da Silva FF, Vicente AA, Teixeira JA. Development and characterization of an environmentally friendly process sequence (autohydrolysis and organosolv) for wheat straw delignification. Appl Biochem Biotechnol. 2011;164:629-41.

22. Sain M, Panthapulakkal S. Bioprocess preparation of wheat straw fibers and their characterization. Ind Crop Prod. 2006;23:1-8.

23. Sun XF, Sun RC, Fowler P, Baird MS. Extraction and characterization of original lignin and hemicelluloses from wheat straw. J Agric Food Chem. 2005;53:860-70.

24. Bijak M, Saluk-Juszczak J, Tsirigotis-Maniecka M, Komorowska H, Wachowicz B, Zaczyńska E, Czarny A, Czechowski F, Nowak P, Pawlaczyk I. The influence of conjugates isolated from Matricaria chamomilla L. on platelets activity and cytotoxicity. Intern J Biol Macromol. 2013;61:218-29.

25. Šutovská M, Capek P, Fraňová S, Pawlaczyk I, Gancarz R. Antitussive and bronchodilatory effects of Lythrum salicaria polysaccharide-polyphenolic conjugate. Int J Biol Macromol. 2012;51:794-9.

26. Stewart D, Wilson HM, Hendra PJ, Morrison IM. Fourier-transform infrared and Raman-spectroscopic study of biochemical and chemical treatments of oak wood (Quercus rubra) and barley (Hordeum vulgare) straw. J Agric Food Chem. 1995:43:2219-25.
27. Faix O. Classification of lignins from different botanical origins by FT-IR spectroscopy. Holzforschung. 1991;45:21-7.

28. Iskalieva A, Yimmou BM, Gogate PR, Horvath M, Horvath PG, Csoka L. Cavitation assisted delignification of wheat straw: a review. Ultrason Sonochem. 2012;19:984-93.

29. Šutovská M, Capek P, Kocmálová M, Fraňová S, Pawlaczyk I, Gancarz R. Characterization and biological activity of Solidago canadensis complex. Intern J Biol Macromol. 2013;52:192-7.

30. Zhbankov RG, Adrianov VM, Marchewka MK. Fourier transform IR and Raman spectroscopy and structure of carbohydrates. J Mol Struct. 1997:436(437):637-54.

31. Pawlaczyk-Graja I, Balicki S, Ziewiecki R, Matulova M, Capek P, Gancarz R. Polyphenolic-polysaccharide conjugates of Sanguisorba officinalis L. with anticoagulant activity mediated mainly by heparin cofactor II. Int J Biol Macromol. 2016;93:1019-29.

32. Zhou Z, Meng Q, Yu Z. Effects of methanogenic inhibitors on methane production and abundances of methanogens and cellulolytic bacteria in in vitro ruminal cultures. Appl Environ Microbiol. 2011;77:2634-9.

33. Jabłoński S, Rodowicz P, Łukaszewicz M. Methanogenic archaea database containing physiological and biochemical characteristics. Int J Syst Evol Microbiol. 2015;65:1360-8.

34. Rogalinski T, Ingram T, Brunner G. Hydrolysis of lignocellulosic biomass in water under elevated temperatures and pressures. J Supercrit Fluids. 2008:47:54-63.

35. Veluchamy C, Kalamdhad AS. Enhanced methane production and its kinetics model of thermally pretreated lignocellulose waste material. Bioresour Technol. 2017:241:1-9.

\section{Submit your next manuscript to BioMed Central and we will help you at every step:}

- We accept pre-submission inquiries

- Our selector tool helps you to find the most relevant journal

- We provide round the clock customer support

- Convenient online submission

- Thorough peer review

- Inclusion in PubMed and all major indexing services

- Maximum visibility for your research

Submit your manuscript at www.biomedcentral com/submit
O Biomed Central 